\title{
Expression of Cultural Resistance in Rajan Mukarung's Poetry
}

\author{
Ramji Timalsina, $\mathrm{PhD}^{1}$
}

\begin{abstract}
What is the value of using ethnic culture in literature written in the mainstream language? For whose benefit is it done so? Rajan Mukarung's latest collection of poems entitled Haataa Jaane Aghillo Raat [The Night Before the Market Day] (2076BS/ AD2019) has shown that it is a strategy of cultural resistance of the marginalized culture against the dominant one. This article is an attempt to show how the marginalized group in a nation can resist the mainstream politics and culture with the use of ethnic culture and deconstruction of the mainstream one in their literary creations. The themes and styles in poetry can show both the representation of the life guided by the subculture and resist the dominance of the next. For this, the theory of cultural resistance developed and used by Michel Foucault, Stuart Hall and Chris Barker has been used. The analysis is based on the interpretation of Mukarung's poems.
\end{abstract}

Keywords: Cultural resistance, mainstream, subculture, ethnic, marginalized.

\section{Background}

Post-1990 or post-2046BS Nepali literature is replete with the idea of identity, freedom and equality. Many creative writers from the marginalized communities appeared with their voice for cultural resistance against the mainstream. Yug Pathak posits that it is the time for new norms and standards for Nepali poetics (189). It is the same period when creative writers and critical thinkers from ethnic communities including Rajan Mukarung started their questioning gesture against the mainstream politics, poetics and aesthetics. Their major focus has been on the use of ethnic cultural myths and emotion of their communities (190). The development of such critical thought in every sphere of Nepali society is reflected through literature and other creative arts (193). It prepared the background for the creation and study of literature from the margin with the light of cultural studies and specifically from that of cultural resistance.

The literary creations of the group with the philosophy of Creative Anarchism (Srijansheel Araajakataa) that includes the ideas and activities of Rajan Mukarung, Hangyug Agyat and Upendra Subba make prominent experiments with this new conscience. Their creation and critical practices focus on exposing ideological varieties found in the Nepali society (Agyat 53). Their next focus has been on cultural diversity that can make literature beautiful and effective at the same time. It means they want to explore the possibilities in the

\footnotetext{
${ }^{1}$ Lecturer, Department of English, Mahendra Multiple Campus, Dharan, Tribhuvan University, Nepal. Email: ramjikoshi@gmail.com
} 
use of ethnic culture in Nepali literature (54). Unlike the traditional Nepali mainstream creations and the third dimensional writing, the creative anarchists aim to construct literature with both the representation of cultural diversity and cultural resistance against the mainstream (55). Critic Abhi Subedi observes: the internally creative tornado of the ethnic Nepali poetry is the reality their life has been undergoing (17). Subedi records the contribution of Rajan Mukarung in the making of such ethnic Nepali poetry. He finds that these ethnic poets and their poetry present the contemporary resistance of political issues (21). On this background, Rajan Mukarung's creations can be studied from the perspective of cultural resistance.

\section{Problem, Objectives, and Methodology}

Rajan Mukarung's latest (the sixth) collection of poems is Haataa Jaane Aghillo Raat [The Night Before the Market Day] (2076BS/AD2019). The poems collected in this book deal with the life of the ethnic Nepali people and their place in the nation. Their suppressed desires and the consequent trauma have been expressed both in terms of the themes and style of these poems. These poems read like the questions raised against the mainstream Nepali culture and the government that wants to strengthen and use the traditional ideology in every sector of national life and culture. So the main issue this article deals with is whether these poems work as the means of cultural resistance that is a part of cultural politics in Nepal or not. To judge this issue, the article tries to answer the following research questions:

- What themes and styles are used in these poems?

- How are themes and styles used as resistance techniques?

- Why are these poems effective as resistance writing?

To answer these questions, this study has used the parameters proposed and practiced by British cultural studies. Based on the research and the critical discourse on the formation and use of cultural (signifying) practices for resistance, cultural studies takes signifying practices including literature as a tool for resisting the mainstream. For this, "[w]ork in cultural studies is, in fact, deeply dependent on the theoretical debates about meaning, identity, representation, and agency" (Culler 44). Unlike the representative current of cultural studies, the resistant current deals with the idea of the use of marginalized culture as a tool for voicing the discontent of the people from the margin.

In this process, it uses the circuit of the culture proposed and used by Stuart Hall. This circuit connects representation, identity, production, consumption and regulation (Hall 1). Placed at the centre is the idea of identity formation through culture and its use for resisting the mainstream culture and its signifying practices. As meaning is believed to be produced and circulated through language, the role of literature is valued high and effective: "Cultural studies includes and encompasses literary studies, examining literature as a particular cultural practice" 
(Culler 44). In this connection, Lois Tyson restates the following questions Stephen Greenblatt uses to study literary works from the angle of cultural studies:

1. What kinds of behavior, what models of practice, does this work seem to enforce?

2. Why might readers at a particular time and place find this work compelling?

3. Are there differences between my values and the values implicit in the work I am reading?

4. Upon what social understanding does the work depend?

5. Whose freedom of thought or movement might be constrained implicitly by this work?

6. What are the larger social structures with which these particular acts of praise or blame, that is the text's apparent ethical orientation, might be connected? (Tyson 297)

These questions help to find how a work of art / literature represents the culture it is based on. Standing upon the same idea of representation as its base, cultural resistance uses some strategies in the creation and circulation of literary works. In relation to literature,

... the work of contemporary cultural studies has centered on questions of subjectivity and identity. Subjectivity, that is, the condition of being a person, is argued to be an outcome of cultural processes, notably the acquisition of language, which bring us into being as 'subject' for ourselves and others. 'Identity', it is said, is best understood not as a fixed entity, but rather as an emotionally charged description of ourselves. Identities are discursive-performative, that is, identity is understood to be the 'effect' of discursive practice that enacts or produces that which it names. (Barker 106)

As a model for this analysis, Russel A. Potter discusses and uses the following tactics for resisting the mainstream through creative works: making the ostensible official significance of words and pictures shiftable, mutable and unreliable; use of vernacular spaces and technologies; defining the speaker's position no matter whether others like or dislike it; using the themes of resistance, critiquing the mainstream, critiquing the state and placing values on the speaker's / writer's history; posing and expressing threat to the mainstream; speaking against the media discrimination; making insurrections against both the homogenized past and the safety-coated present; reappropriating myths and mythical signs ("to break apart the abstracted, mythical signs and ... reinscribe it in a counter-mythical system") (458-467). This article uses the same parameters to analyse Mukarung's poems. 


\section{Ethnic Nepali Literature and Mukarung's Writings: A Review of Literature}

Critics have placed Rajan Mukarung's creative writings under a large national issue of ethnic identity politics and the subsequent creative practices through literature. Sushant Gurung argues that Rajan's writing gives the power of voice to the marginalized culture, language and religion. Mukarung has used, according to Gurung, many terms from the ethnic Kirat languages. These are the techniques prominently used, in a form of campaign, by creative anarchists. Their focus is to turn the anarchy into creativity (46). Critic Govinda Raj Bhattarai takes such a practice to be the creation of system out of absurdist atmosphere. Such a system, Bhattarai observes, uses new techniques for the creation of disciplined poetry that shows the ways to correct the track of history that is filled with athoughts in their understanding. Bhattarai takes their attempts as digressions from the traditional system of poetry. On the surface, they look like apoetry, but in depth their poems are full of poetic vigour. Finally, Bhattarai places this trend under multisided theory/atheory of postmodernism (. . A Ainaa 143). These studies show the different current of thought and practices of creative anarchists.

Bhattarai further highlights their focus on centreless plurality and the desire for anarchy that reflect the life the ethnic Nepali people live (. . Ainaa 153). He extends this discussion in his next book Uttaraadhunik Vimarsha [Postmodern Discourse]. He declares that the truths that have been believed to be established have already slipped away. He has further argued that Nepali literature, by the beginning of the new millennium (AD2000), has captured a high speed of transformation. It is full of attempts to sideline the old tradition and establish the new ideas, concepts, practices, styles and strategies (413). Rajan Mukarung's place in Nepali literature should be sought somewhere in this new trend.

The major focus of Mukarung and his / their movement is to try to connect poetry with society. Hrishiraj Baral observes that poetry can live long only with its connection with life and immediate social concerns. It is the growing trend in Nepali literature. As a part of this growth, the last decade was the time of satire, rebellion, struggle, resistance and revolution (373). So the creations of this period are connected with the stand of the poets and how the creation is connected with human life (374). The growth of identity politics has created a new challenge for creators, too (379). As Nepali poetry is the genre closest to Nepali society (390), we can see the value of Mukarung's writing in the same connection.

Critic Purushottam Subedi finds that poetry is not politics; but in the absence of politicosocial concern, the beauty of poetry is not complete. He observes that the simplicity connected with social reality and the search for honesty in expression has made contemporary Nepali poetry responsible and committed (40). Subedi believes that contemporary Nepali poetry has tried to show its face filled with social welfare (46). It is in line with critic Chaitanya's opinion that poetry needs to expose and motivate the people for community based commitment rising above the individual based commitment (122). Such a commitment can lead to creative 
imagination, emotional energy and originality that finally supply linguistic vigour, skill of expression, choice and use of imagery, symbol and metaphors (123). The creations of the creative anarchists including that of Rajan Mukarung belong to the same trend.

Critic Abhi Subedi has praised ethnic Nepali poetry and Mukarung's creations for the use of diversity, freshness, worries of life and creative experiments. He observes that the poems by ethnic Nepali poets present the conflict created by the use of ethnic language terms in Nepali. These conflicts display the contact zones of Nepali society and its contemporary discourse. But still there lacks the study and analysis of their level of poetic conscience (21). However, Subedi expresses his confidence that ethnic Nepali poetry has added a new type of liveliness in Nepali poetry with the use of style, expression-system and poetic projection (22). Geography and border along with nature and maps are major aspects of ethnic Nepali discourses (26). All types of ethnic Nepali poems have used the conscience of existence and identity (27). In this trend, Rajan Mukarung's poetry, Subedi finds, is expressive of the micro-social circumstances and identity oriented political consciousness (23). He is able to use expressions with minute planning and arrangement (51). Here lies the artistic value of his creations.

After the publication of his sixth collection of poems Haataa Jaane Aghillo Raat [The Night Before the Market Day] (2076BS/AD2019), critic Taralal Shrestha reviewed the book defending the cause of Mukarung's poetry and its social value. Shrestha argues that Mukarung's poetry threatens the so called mainstream through the stories filled with fire. Mukarung's pleading for original identity, Shrestha adds, is a common human trait. At a time when critical mass is depleting in the nation, these poems present the speakers with critical conscience. Shrestha finds the poet a rebel, revolutionary, anarchist and anti-establishmentarian because he is angry with the ugly broker-government and its super-structure. Shrestha further argues that Mukarung pleads for the life with culture and humanity. For this, his poems present the real picture of the present Nepali society. So, it presents the taste different from the taste of the rulers and their followers, and so can make these people unhappy. Shrestha concludes that there lies the success of Mukarung's poetry.

The above mentioned critical readings of Mukarung's poems and other creativities just highlight the trend and tenets of his writings. There is a lack of detailed study on how his poems use culture as its basis of creativity and how the same use of culture gives the base for the resistance against the mainstream socio-political norms, values and culture. The following discussion concentrates on the same.

\section{Resistance through Themes and Styles of the Poems}

Mukarung's Haataa Jaane Aghillo Raat [The Night Before the Market Day] (2076BS/AD2019) uses both the themes and styles to resist the Nepali mainstream culture. Mukarung, who himself is a living symbol of such resistance in his real life and literature, starts the series of resistance from the title and cover page. The word "haataa" is the ethnic tone of 
the standard Nepali word "haat". Similarly, the painting on the cover page presents a group of Mangolian people who look at the smeared face Mangolian lady. Though her face is red smeared, it is clear from her hair style and the ornaments in her ears and hand that she is a Mangolian one and so an ethnic citizen of Nepal. It represents the smeared faced Sumnima, the first mother or mother-nature of the Mangolian people in Nepal. When the mother is cast as smeared faced, the whole section of ethnic Nepali citizenry is shown to have lost their charms on the face, i.e. their identity. The awe-struck traumatic appearances of the people who look at her are painted in light black. This symbolizes the condition of the people who are put in the semi-darkness for long by the state. And the effect is trauma in their everyday life. The same colour used for the face of the lady and title of the book also indicates that the poems deal with the marginalization, shock and identity crisis of ethnic Nepali citizens.

Many poems in the anthology directly deal with the idea of resistance against the mainstream and its authoritarian government. The very first poem of the book "Anurodh" ["Request"] compares the government and the flood of technology cum social media including the facebook, instagram and twitter. Both of the government and social media, the speaker first feels and then argues, are busy destroying the life of the landless people. So, the poem ends at the lines: "'Sabailaaee surakshit rahan huna anurodh chha!'/ Hekka rahos!/ Baadheesita hoin, sarakaarsita! ['I request everybody to remain safe!'/ Mind it!/ Not with the flood, but with the government!]" (11. 14-16). This is the indication that the government is a terrorist against its people.

Similarly, the second poem entitled "Roteping" ["Merry-Go-Round"] compares the mover of the rotary swing with the government. Just like the mover moves the swing at his own will and takes the participants sometimes atop the swing and the other time at the bottom at his own desired pace; so does the government in its dealing with the ethnic people. Just like the mover is appointed by unknown power that possesses the swing, so is the government that is just a caretaker appointed by some cultural force to work upon the rest. So, the ethnic people do not feel good once they come out of the swing: "kina .../ ringaataa laagchha?/ waakawaakee huncha? [Why .../ Do we feel dizzy?/ Feel vomiting?]" (11. 22-23). So the speaker of the third poem realizes that the ethnic community needs to continue their cultural war against those who manage the political system in the nation (12). This theme of resistance continues in other poems, too.

"Tyahaa" ["There"] is another poem with the same theme. The speaker suspects that there is somebody behind the scene who manages the show. That hidden force uses other seen representatives such as businessmen, officials, teachers, police, army, poets, writers, journalists or artists to bargain about / on the thigh of beautiful lass. That power behind the scene is further equated with the present government of Nepal that sings the song of socialism; declares the end of capitalism; and discourages people to talk of the nose, the eye, the caste, the gender and the region. Instead, it encourages the people to worry about and work for the prosperity. But it is 
fearful of the idea of reservation encoded in the constitution of the nation; and is busy putting the term 'secularity' under a red mark. At last, the speaker reveals the identity of that hidden force: "uhee bhaneko yahee sarakaar ho / jo tapaaeeko kanchatmaa pestol taakiraheko chha [That 'it' is the same government / that is aiming the pistol at your brow]" (19). This is a direct attack upon the present government and the culture it is based on.

In the next poem entitled "Raajeenaamaa" ["Resignation"], the poet compares the government with a bull:

Nagaree khaaneharooko yo kaantipuree nagareemaa

Phohorako dangur chabaaudai

Ugraairaheko uhee saandhe

Phinja kaadee dukrirahechha - dijital kyaameraamaa

Raatreebhojako poja khichaairahechha nijee aspataalamaa

[In this Kantipuri City of those who do not work, but eat

There is the same bull

That is munching the heap of the dirt and is chewing the cud

Frothing and bellowing — in a digital camera

And is giving a pose after a feast in a private hospital.] (31)

When the poet has to experience all these, he is very angry with the government, the culture and the people who manage it. Then he begins to see the eyes of the so called nationalist leader in the tomatoes, the face of the nation-devoted official in a mango, the body of the young leader as bitter-gourd and the bikini-organ of a popular female leader in an apple. And finally, he imagines cutting each of these fruits and vegetables on a chopping board. Turned into small pieces after fierce cut, they all are thrown into a dustbin (78). This action and the images used here are great symbols that carry on the anger and desire for revenge that the government authority has created in the mind of the ethnic people of the nation.

These poems remind us of Michel Foucault who observes: “. . . no matter how terrifying a given system may be, there always remain the possibilities of resistance, disobedience, and oppositional groupings" (165). They work, Stephen Duncombe argues, as the site of cultural resistance that becomes "a safe place to hide" (5). Mukarung's many other poems are the examples of this argument. Unlike the poems discussed above that directly attack on the mainstream culture and politics, the poems entitled "Huna Nasakeko Geet" ["Unmade Song"], "Maailaa Laamaa" ["The Second Lama"], "Kedaambeko Aatmaa" ["Kedambe's Soul”], 
"Aago" ["Fire"], and "Uttar-aadhunik Bhanubhakta" ["Postmodern Bhanubhakta"] artistically and so indirectly criticize and threaten the mainstream.

In the poem "Huna Nasakeko Geet" ["Unmade Song"], the poet has presented the speaker as a representative of the ruling class. He is an outsider who does not have a long legacy in this nation (room). He is unable to internalize the reality, beauty and quality of this nation. So, he ultimately realizes that he does not have the softness of the flowers that bloom in this nation; does not have the zeal and concentration of the air that flows here; and does not have the speed of the river or a beautiful human in the heart. The speaker feels that he has only collected a lot of repressed desires, a lot of ego, a tattered heart without its pulse and a life devoid of any culture. As he and his forefathers have already left their place of origin, their originality is not with them. The place where he lives now is prepared by others. It has been forcefully captured with the use of hypocrisy and controlled by governance. So, it is not possible for him to feel light and happy and be a song. What he can simply do is write a song and realize his outsidedness when he cannot become a song here (26-27). The crux of the poem is the poet's idea that the rulers of Nepal are not its original people. They are simply outsiders and so really do not have the right to rule this nation. They are culturally outsiders who cannot, even themselves, be happy in its original sense in this land.

The similar idea of cultural difference is found in the poem "Maailaa Laamaa" ["The Second Lama"]. The character / speaker continues his resistance through musical presentation. He has short-eye-sight, poor hearing and amputated fingers. So, he cannot directly attack the enemies who were his friends in the past. When these friends forgot their commitment and ideal and left him alone at the crossroad, he cannot call them 'comrade', but only the friends and goes on singing at the same place against their so called mainstream protected by the gun, the jail and the conspiracy (38-39). Though this poem seems to be a direct attack on his communist friends with whom he worked for many years before they won the election and started to rule the nation, exactly it is an attack on such tendencies of the rulers. They use the artists, the poor, the weak and the proletariat as components of the ladder to step up to the ruing chair. Once they are the rulers, they see the same people, who made their ladder, enemies. It is how their cruelty of the heart, i.e. the heart of the mainstream, is exposed.

The next poem "Kedambe's Soul" also attacks the so called high class mainstream. Kedambe is an ethnic speaker who has killed this master and the master's son before he committed suicide. The reason is: At the time when he was very happy to feel a growing baby in his wife's womb, she revealed that the baby was not his. Even she was confused whether the baby was that of the master or his son's. Now, he does not like to term his own death as 'suicide', but only an 'untimely pass', the term the ethnic people use for such end of life. The soul of such people is believed to trouble the living people. So, now he is troubling the master's wife. Thus, this poem shows the effect of the tussle between the ruler's and the ruled's cultures and behaviours. 
These poems show that "cultural resistance often speaks in a more familiar and less demanding voice than political dissent. It makes this move even easier. In this way, cultural resistance works as a sort of stepping stone into political activity" (Duncombe 6). And the resistance is valued with its relation with the values one cherishes. What we find is that "all cultures are decidedly not of equal virtue when measured against 'our' values" (Barker 71). The poem entitled "Aago" ["Fire"] symbolically presents this. The fire possesses both the creative and destructive powers of the ethnic people. Based on the stories of fire from Mundhum, the poem starts: "Aagolaaee jiskaaunu hunna bhanne timeelaaee thaahaa chaa. [You know you should not tease the fire]" (1. 1). Here, the speaker is an ethnic one and the 'you' is the person who represents the mainstream. The poem ends at the lines: "tyahee agultomaa salkiraheko aago / tyahee aago ta ho timeele nadekheko [The fire spreading through the fire brand / It is the same fire that you have not seen.]" (48). It symbolically presents the suppressed and so destructive anger that is growing in the ethnic community. It may destroy the mainstream at any time. The use of cultural / mythical reference from the holy practice to oppose the suppressor is one tactic of the writings designed for cultural resistance.

"Post-modern Bhanubhakta" is a poem that uses mainstream cultural symbols to attack the mainstream itself. At first, the poet deconstructs the symbol of Bhanubhakta following the trend of the last decade to do so. Bhanubhakta is taken as a national emblem in Nepal. He is respected as the aadikavi [the first poet] of the nation. His writing of the epic Ramayana is believed to have strengthened and spread Nepali national unity through language i.e. Nepali and national emotion through poetry. But recently his contribution has been put under question. People who plead for ethnic nationalism question the position given to him; and those who are in the mainstream, with the belief on civic nationalism, plead for the continuity of his position. Rajan Mukarung and Yug Pathak are two writers who regularly question Bhanubhakta's contribution. Pathak has depicted Bhanubhakta as a creator of the hegemonic language and culture that the mainstream Nepali society and its government have established. The statues of Bhanubhakta were constructed from Darjeeling to Dhangadhi. But in recent decades, many of them have been physically destroyed (182-188). This is the deconstruction of social attitude towards Bhanubhakta.

Mukarung, in this poem, rationally destroys the traditional image of Bhanubhakta and equates him with a broker and a new Hanuman in the nation. He terms his Ramayana "dalaal raamaayana" [broker Ramayana] and lashes him for writing the poems for the education of the daughter-in-laws that instructs them to confine themselves within the boundary of their home (68). Mukarung, here, presents Bhanubhakta as the speaker in the poem. This speaker is dazzled to see the postmodern daughter-in-laws carrying the flag on March 8 and defying his instructions. So, Bhanubhakta is terrified at present. Mukarung deconstructs the action of the Rama, the Tara, the Bali, the Sugriva, the Ravana, the Kumbhakarna, the Vibheeshana, the Sita 
and many other mythical figures Bhanubhkta has presented in his epic. It is how the resistance against the established culture is conducted in Mukarung's poetry.

Mukarung's use of the life of the ethnic people in his poems carries his theme of resistance and an appropriate style to deal with it at the same time. The title poem "The Night Before the Market Day" is a good example in this respect. In Nepali ethnic settlements in the hills, the people gather at a certain point once a week for marketing. They carry their goods for sale and purchase what they need. The young ladies visit it only in some occasions with the permission from their parents for special purchases. The speaker of this poem is such a young lady who is a typical kiratini (Kirati girl) who wants to sell a basketful of dreams [ek perungo sapanaa] (1. 2). Her dreams are in the forms of plum, fern, mushroom, pungent chillies, millet and other home made products. She has to purchase the objects of her need with the money collected from the sales. This speaker takes this exchange not simply as an exchange of goods but as a barter of life. Here lies the meaning of the poem.

The poem presents what may happen to her at the marketplace. It is her guess for this year based on the previous experiences she has undergone there. From the very first of her stops in the marketplace, people, whom she meets, start to lure her. Their intention is to take undue benefit of her beauty and youth. It is her compulsion to visit the place; but it is full of dangers. After the description of possible dangers and its causes, she finally decides to carry a sickle for her safety. It shows the contrast between the ethnic and mainstream society and culture. All the people the lady imagines to meet in the marketplace represent the mainstream that is ready to take benefit of an ethnic young woman in different ways. And, thus, the use of the image and symbol of the sickle is the sign of compulsive resistance against the mainstream.

From the perspective of cultural studies, it is believed that "symbols, myths, novels, plays and other practices with an affective dimension are more effective politically than are rationally and logically constructed arguments" (Barker 107). In this respect, too, Mukarung's poems display the significant qualities as his use of cultural politics is a part of "a series of collective social struggles organized around the nodal points of class, gender, race, sexuality, age, and so forth, that seek to redescribe the social in terms of specific values and hoped-for consequences" (Barker 107). The observation by Abhi Subedi also highlights the same: there are many important aspects in ethnic Nepali literature that can be clear only with the study of the tradition and minute aspects these languages carry on (17). Mukarung uses the ethnic vernacular of the Nepali language and provides a good example for these theoretical logics.

This is also a resistance strategy with the use of the external power for the defense of the culture the user of resistance is based on. Barker also believes that

[r]esistance is an essentially defensive relationship to cultural power experienced as external and 'other' by subordinate social forces. Here, resistance issues from relationships of power and subordination where a dominating culture is seeking to 
impose itself on subordinate cultures from without. Consequently, resources of resistance are to be obtained in some measures outside of the dominating culture. (171)

Mukarung's writing does the same: it represents the ethnic culture and uses it as the resistance resource against the mainstream. The words like "bhaalegiddha" in place of "bhaaleyuddha" in standard Nepali to mean the cock fight, "bhattipasal" instead of "bhatti" to mean the pub, "daai" for mother, "jotnaa" for "jotna" to mean ploughing, and "betee" for "chhoree" to mean a daughter are only a few examples used in the poems of this collection. Such uses of the words with the tones and tunes of the ethnic vernacular of Nepali language not only raise the value of these communities, but also extend the respect to the speaker's place, standpoint and reality.

Deconstruction of the mainstream Nepali myths and mythical figures also give space for new thoughts. The poet argues that the "dhanu" [The bow Ram broke to win Sita for marriage] was allowed to be broken just once. If it is repeated, even the ethnic hero may break it to win modern Sitas. In the Ramayana, Suparnakha is humiliated with the slashing of her nose. But the poet uses the same myth in case of a modern hot-cake actress who becomes beautiful slashing her nose and getting its plastic surgery. The same action that used to destroy the beauty of a lady is now makes her attractive. This attack on the mainstream culture is a tactic used in the resistance writing. The poet has deconstructed the images of the teacher, brother, husband and lover. The postmodern Draupadi is not shy in the exposure of her sex organ; instead, she is ready to expose everything to the society that binds her using the sex as a symbol of morality (62). The traditional "damaai charo" [tailor bird] is a "shilpee charo" [artist bird] for the poet (75). At the same time the use of the ethnic cultural myths including the myths from the Mundhum, and ethnic images such as bukiphool (41), bindi, surti, chakmak, dalchhin dhungaa, jhulo, and agenaa (40) has made the resistance effective.

\section{Conclusion}

Rajan Mukarung's poems display the themes and styles of cultural resistance writing. Many poems directly deal with the theme of ethnic resistance against Nepali mainstream politics and culture. The use of threat, criticism of the mainstream along with the valuization of the speaker's history and culture; and presentation of lively picture of the marginalized has made these poems good examples of resistance writing in Nepali literature. He has made use of colloquial tone and tune of the ethnic people when they speak the Nepali language, respect to the place and reality of the speaker, satire against the mainstream media, attack on homogenized past and safety-coated present, use of ethnic myths and deconstruction of mainstream myths, use of cultural images and symbols, revolutionary expressions and traumatic psychology of the speaker. These poems are the soft means of resisting the ruling mainstream in Nepal; and so they provide some help to the larger issue of political representation and resistance in the nation. His poems and other writings demand further and detailed studies from the perspective of cultural resistance. 


\section{Works Cited}

Agyat, Hangyug. "Samanvit / Samavishan-Srijansheel Araajaataako Tesro Varsha." ["Associated / Inclusion - the Third Year of Creative Anarchists."] Vimarsha Weekly, vol. 1, no. 1, 2011, pp. 53-55.

Baral, Hrishiraj. Maarksavaad Ra Sabaaltarn Adhyayan [Marxism and Subaltern Studies]. Sajha, 2073BS.

Barker, Chris. Making Sense of Cultural Studies: Central Problems and Critical Debates. Sage, 2002.

Bhattarai, Govinda Raj. Uttaraadhunik Ainaa [Postmodern Mirror]. Ratna Books, 2062BS.

---. Uttaraadhunik Vimarsha [Postmodern Discourse]. Modern Books, 2064BS.

Chaitanya. Maarksavaadee Kalaadristi Ra Samikshaa [Marxist Aesthetics and Criticism]. 2nd ed. Airawati, 2064BS.

Culler, Jonathan. Literary Theory. Oxford UP, 1997.

Duncombe, Stephen, editor. Cultural Resistance Reader. Adarsha Books, 2012.

During, Simon, editor. The Cultural Studies Reader. 3rd ed. Routledge, 2012.

Foucault, Michel. "Space, Power and Knowledge.” During, pp. 164-171.

Gurung, Sushant. "Samayako Damadaar Diskors." ["Powerful Discourse of Time.”] Nepal, 25 Chaitra 2069BS, p. 46.

Hall, Stuart. "Introduction." Representation: Cultural Representation and Signifying Practices, edited by Stuart Hall, The Open U, 1997, pp. 1-11.

Mukarung, Rajan. Haataa Jaane Aghillo Raat [The Night Before the Market Day]. Upendra Subba and Tirtha Sangam Rai, 2076BS.

Pathak, Yug. Maangenaa: Nepaal Manthan [Reestablishing the Honour: Nepal Discourse]. Fine Prints, 2074BS.

Potter, Russell A. “History-Spectacle-Resistance.” During, pp. 457-474.

Shrestha, Taralal. "Kaavyik Raajniti." ["Poetic Politics."] Kantipur Koseli, Bhadra 21, 2076BS. www.ekantipur.org.

Subedi, Abhi. "Samakaaleen Nepaalee Kavitaamaa Janajaateeya Chetanaa." ["Ethnic Consciousness in Contemporary Nepali Poetry."] Pragya Samakaaleen Nepaalee Kavitaa Vimarsha [Academy Contemporary Nepali Poetry Discourse], edited by Amar Giri, Hemanath Paudel and Laxmanprasad Gautam, Nepal Academy, 2072BS, pp. 15-70.

Subedi, Purushottam. Sangkramanako Saahitya Ra Samakaaleenataa [Poetry of Transition and Contemporariness]. Sajha, 2066BS.

Tyson, Lois. Critical Theory Today: A User-friendly Guide. 2nd ed. Routledge, 2008. 